\title{
Influence of flood risk characteristics on flood insurance demand: a comparison between Germany and the Netherlands
}

\author{
I. Seifert ${ }^{1}$, W. J. W. Botzen ${ }^{2}$, H. Kreibich ${ }^{3}$, and J. C. J. H. Aerts ${ }^{2}$ \\ ${ }^{1}$ Norwegian Institute for Water Research (NIVA), Section for Climate and Environmental modelling, Oslo, Norway \\ ${ }^{2}$ Institute for Environmental Studies, VU University, Amsterdam, the Netherlands \\ ${ }^{3}$ Section Hydrology, German Research Centre for Geosciences (GFZ), Potsdam, Germany \\ Correspondence to: W. J. W. Botzen (wouter.botzen@ivm.vu.nl)
}

Received: 10 August 2012 - Published in Nat. Hazards Earth Syst. Sci. Discuss.: Revised: 7 May 2013 - Accepted: 7 May 2013 - Published: 1 July 2013

\begin{abstract}
The existence of sufficient demand for insurance coverage against infrequent losses is important for the adequate function of insurance markets for natural disaster risks. This study investigates how characteristics of flood risk influence household flood insurance demand based on household surveys undertaken in Germany and the Netherlands. Our analyses confirm the hypothesis that willingness to pay (WTP) for insurance against medium-probability mediumimpact flood risk in Germany is higher than WTP for insurance against low-probability high-impact flood risk in the Netherlands. These differences in WTP can be related to differences in flood experience, individual risk perceptions, and the charity hazard. In both countries there is a need to stimulate flood insurance demand if a relevant role of private insurance in flood loss compensation is regarded as desirable, for example, by making flood insurance compulsory or by designing information campaigns.
\end{abstract}

\section{Introduction}

In Central and Northern Europe, it is expected that flood risk will increase as a result of climate change and socioeconomic development, such as increasing flood plain occupancy (e.g. Hall et al., 2003; CEA, 2005; Kundzewizc et al., 2005). Risk is defined here as the combination of the probability of a particular event and of the damage that this event would cause if it occurred (Kron, 2005). Effective compensation schemes for flood damage may ameliorate the impacts of flooding. Even though insurance markets in the European member states are regulated by various directives (e.g. EC, 2007), their flood loss compensation schemes differ (Schwarze and Wagner, 2009). These differences have partly arisen out of varying views on the roles that private insurers or the public sector ought to play in the compensation of natural disaster losses, but may also be influenced by the different characteristics of the flood risk faced by member states (Bouwer et al., 2007).

A possible obstacle for an adequately functioning flood insurance system is that individuals need to "play their role" in the system and buy insurance. Several studies have shown that in practice many people do not make the rational tradeoffs between the costs of insurance and its expected benefits in terms of reduced risk as has been assumed by expected utility theory, which is the traditional economic theory of individual decision-making under risk (Kunreuther, 1984; Kunreuther and Pauly, 2004; Krantz and Kunreuther, 2007). For instance, many homeowners in the USA do not purchase flood insurance even for premiums that are close to the expected loss or that are in some instances even subsidised (Dixon et al., 2006), while expected utility theory predicts that risk-averse individuals would purchase insurance for such premiums. An explanation for this behaviour is that these individuals neglect the low-probability flood risk. But it has also been observed that many people overestimate lowprobability high-impact risk, and purchase insurance against such risk even if premiums are considerably above the expected loss (McClelland et al., 1993; Botzen and van den Bergh, 2009; Laury et al., 2009). These behavioural biases, which are rooted in prospect theory, may be less severe in the case of medium-probability medium-impact flood risk (Botzen and van den Bergh, 2009). 
This study examines how characteristics of flood risk influence household flood insurance demand. This is done by comparing results of stated preference surveys of flood insurance demand in the Netherlands, where floods have a very low probability but can be catastrophic, with a similar survey conducted in Germany where flood probabilities are higher than in the Netherlands and flood impacts are likely to be less severe. We believe that the comparison of flood insurance demand between the Netherlands and Germany is of special interests for three main reasons: (1) these countries have very different levels of flood risks which provides an interesting case study for examining how these differences influence demand for flood insurance; (2) these bordering countries have in general rather similar cultures which allows for comparing flood insurance demand against the background of differences in flood risks; and (3) in both countries there have been discussions to change existing arrangements for flood loss compensation and insights into flood insurance demand provide useful information for such discussions.

Differences in flood risks between Germany and the Netherlands are likely to result in differences between individual experiences with flooding and flood risk perceptions in these countries, which are commonly regarded as important factors influencing flood insurance demand (Kunreuther et al., 2009). Moreover, differences in risks may have influenced the different flood loss compensation schemes that are in place in Germany and the Netherlands. In this study we will examine how flood experience and flood risk perceptions influence flood insurance demand given the different characteristics of flood risks between these countries and institutional arrangements for compensation of flood losses.

In general, insurance coverage for flood damage is excluded from the usual property insurance policies in the Netherlands, but households may receive partial compensation for flood damage from the government. Flood insurance could provide more certainty for obtaining financial compensation for flood damage than the government compensation which is uncertain. Private insurers provide coverage against flood damage in Germany, albeit to a limited extent. On particular occasions the German government provided generous relief of flood damage (Thieken et al., 2006). The compensation schemes in both countries have been criticised as being inefficient ${ }^{1}$ to accommodate the expected increase in future flood risk, and suggestions have been made that insurers take on a larger role in flood loss compensation. In particular, a public-private flood insurance has been proposed for the Netherlands (Jongejan and Barrieu, 2008; Botzen and

1 The compensation scheme in the Netherlands has been criticised for its uncertainty about whether flood damage will be compensated, and if so how much compensation will be provided. Moreover, the compensation scheme does not provide incentives to households to adequately prepare for flooding and take measures that limit flood damage. An often-mentioned problem with the German flood insurance system is that the market penetration is low (see Sect. 2). van den Bergh, 2008), while a compulsory public-private natural disaster insurance has been discussed for Germany (Schwarze and Wagner, 2007). It is, therefore, of interest to arrive at insights into whether sufficient demand exists for the proposed flood insurance in the Netherlands, and whether natural disaster insurance in Germany should be made compulsory. Such insights can be useful for policy makers who are involved in the design of flood insurance schemes and for insurance companies, while several of our hypotheses that will be tested (Sect. 3) may be of interest for fellow scientists.

The remainder of this paper is structured as follows. Section 2 examines characteristics of flood risks and describes the financial arrangements for compensation of flood damage in Germany and the Netherlands. Section 3 outlines the theoretical framework. Section 4 describes the surveys used to collect data on flood insurance demand and the statistical methods applied. Section 5 provides the results. Section 6 concludes.

\section{Flood risk and arrangements for compensating flood damage in Germany and the Netherlands}

\subsection{Characteristics of flood risk in the two countries}

Germany and the Netherlands face similar flood hazards; both countries are at risk of storm surges, river floods and flash floods (Berz et al., 2001; Jonkman, 2005; Kron, 2005). However, flood risk, in terms of flood probability and damage, is different in these two countries, as is apparent from Table 1. We define a flood as the inundation of land that is normally dry, which is caused by high water levels in rivers or high levels of sea water resulting from storm surge. Flood probabilities differ because of distinct water management practices, which may be explained by differences in topography. In the Netherlands most areas are located below sea level or in the potential flood zone of a river. The lowlying areas in the Netherlands need to be protected by flood protection infrastructure to prevent flooding, which has resulted in higher flood protection standards, i.e. lower probabilities for inundation, than in Germany. As an illustration, flood protection standards are between the probabilities of $1 / 10$ and $1 / 100$ in the German part of the Elbe River (IKSE, 2003), and $1 / 200$ to $1 / 500$ in the German part of the Rhine River with an exceptionally high protection standard up to $1 / 1000$ at parts of the upper Rhine River in Germany (te Linde et al., 2011). German coastal flood protection varies between 1/100 at the Schleswig-Holstein North Sea coast and 1/400 in the city of Hamburg (Policy Research Corporation, 2009). The organisation and administration of flood defence in Germany is the sole responsibility of the state governments. Hence, decision-making on safety standards does not follow a uniform path but is driven by many individual political decisions in the different states. Flood protection 
standards are between $1 / 1250$ and $1 / 10000$ (near the coast) in the Netherlands (Aerts et al., 2008). Flood protection standards in the Netherlands were determined after the major flood disaster in 1953 and these standards were guided by a cost-benefit analysis (van Dantzig, 1956). These higher flood protection standards in the Netherlands are justified from an economic perspective since potential flood damage is larger than in Germany. This can be explained by the potentially large areas that can be inundated in the flat river valleys in the Netherlands with wide flood plains, such as the lower Rhine delta. Moreover, the Netherlands is almost twice as densely populated as Germany and has a high concentration of economic values in the river delta, so that the financial exposure to flooding is large. In Germany, the area potentially affected by river floods is comparatively small, because many river valleys in the south and central parts of the country are narrow. Nevertheless, a $\mathrm{HQ}_{100}$ Elbe River flood event would flood more than $1000 \mathrm{~km}^{2}$ in Germany and would affect about 34000 people in 53 cities (IKSE, 2001, 2003).

As an illustration of the differences in potential damage, the Rhine Atlas estimated that total potential flood damage along the Rhine is $€ 34$ billion in Germany and $€ 131$ billion in the Netherlands (ICPR, 2001). ${ }^{2}$ Apart from the potential damage of river flooding, damage caused by the overtopping or failure of coastal protection may result in catastrophic damage in the Netherlands of up to $€ 100$ billion or more (Aerts et al., 2008).

\subsection{The insurability problem of flood risk}

Flood risks, like storm surges and river floods, are characterised as low-probability high-impact events, which are difficult to insure in private markets (Kron, 2009). Insurability of low-frequency flood risk is more complicated than, for example, fire risk, since uncertainty about flood risk is relatively large. This is the case because fires occur more regularly than extreme floods, which implies that more historical loss observations of fire are available on which insurance premiums can be based. Moreover, an important problem with insuring flood risk is that the individual risks are not independent of the occurrence of the risk in time and space. Flood risks are correlated, which means that insurers can suffer many losses during a single flood event. In other words, the law of large numbers - that implies that the variance of the mean value of loss declines if more independent risks are pooled - does not apply, and the volatility of losses may increase if more insurance policies are sold (Grossi and Kunreuther, 2005). This may be especially prob-

\footnotetext{
${ }^{2}$ It should be noted that the damage projections for the Netherlands may underestimate potential damage compared with Germany since indirect damage, destruction of infrastructure, and high loss potentials of intensive agriculture are not accounted for. These are expected to be more important in the Netherlands than in Germany, because of higher expected flood depths and flood duration in the Netherlands (ICPR, 2001).
}

lematic when insuring floods in regions with a high potential damage where total claims can be larger than the underwriting capacity of insurers. Insuring correlated flood losses is costly which implies that insurers may only provide flood insurance if they can charge premiums that considerably exceed the expected flood loss (Kunreuther et al., 2009). Moreover, demand for insurance products needs to be sufficiently high so that enough revenue is generated to pay for the reimbursements of claims.

\subsection{Financial arrangements for flood damage in Germany}

Most insurance companies in Germany offer an optional insurance coverage for natural hazards - including floods - in addition to the standard building or household contents insurance. The natural hazard insurance in Germany bundles the risks of flooding, earthquake, land subsidence, landslide, snow pressure, and avalanches (König, 2006). To support decisions of insurers as to whether, and under what conditions, a property can be insured, the German Insurance Association (GDV) developed a zoning system called "ZÜRS", which is based on flood maps, in order to distinguish areas with a different flood probability (GDV, 2008; de Moel et al., 2009). The majority of properties are located in exposure zone 1 (with a flood probability lower than $1 / 200 \mathrm{yr}$ ), which means that they are regarded as insurable. Approximately $10 \%$ to $12 \%$ of total properties are in exposure zone 2 (with a flood probability between $1 / 50$ and $1 / 200 \mathrm{yr}$ ) and only $3 \%$ of properties are located in exposure zones 3 and 4 (with a flood probability of between $1 / 10$ and $1 / 50 \mathrm{yr}$, and $1 / 10 \mathrm{yr}$, respectively), meaning that they have a high likelihood of being flooded (GDV, 2008). Properties in zone 4 are considered uninsurable, whereas properties in exposure zones 2 and 3 can only be insured cpolicy conditions, such as a higher deductible.

Today, the average market penetration of natural hazard insurance is between $3 \%$ and $4 \%$ in combination with building insurance, and $10 \%$ in combination with household contents insurance (GDV, 2003; Landtag Rheinland-Pfalz, 2005; Bogenrieder, 2004), but these numbers can be significantly higher in some federal states due to historical reasons. For instance, estimates of the market penetration of natural hazard insurance in combination with household contents insurance in Eastern Germany (area of the former GDR) varies between $90 \%$ (DKKV, 2003) and $60 \%$ to $70 \%$ (Graff, 2000).

The German government has compensated flood losses in the past after severe flood events, but there is no legal obligation to do so. The introduction of compulsory flood insurance backed by a state guarantee for extreme losses was discussed in Germany after the severe flood event in 2002 (e.g. Schwarze and Wagner, 2007). In the end, it was not introduced mainly because the politicians perceived high costs for the state guarantee, there were legal objections against the compulsory nature of the insurance, conflicts existed 
Table 1. Characteristics of flood risks where inundation up to the dyke hinterland and possible damage is involved in the Netherlands and Germany, including flood experiences between 1950 and 2011.

\begin{tabular}{|c|c|c|}
\hline Flood risk characteristics & The Netherlands & Germany \\
\hline $\begin{array}{l}\text { Flood probability in areas with } \\
\text { flood protection infrastructure }\end{array}$ & Between $1 / 1250$ and $1 / 10000$ & Between $1 / 10$ and $1 / 500$, exceptionally up to $1 / 1000$ \\
\hline $\begin{array}{l}\text { Average potential flood damage } \\
\text { per residential building (in } 2012 \\
\text { values) }\end{array}$ & $\begin{array}{l}€ 70000 \text { average damage per residential building in the } \\
\text { Dutch river delta with a flood probability of } 1 / 1250 \\
\text { (Botzen and van den Bergh, 2012b) }\end{array}$ & $\begin{array}{l}€ 47960 \text { average damage to residential buildings during } \\
\text { 2002, } 2005 \text { and } 2006 \text { floods in the Elbe and Danube } \\
\text { catchments (estimated from Thieken et al., 2010) }\end{array}$ \\
\hline $\begin{array}{l}\text { Flood experiences (date, dam- } \\
\text { age, total affected, deaths from } \\
\text { floods between } 1950 \text { and } 2011 \\
\text { recorded in EM-DAT }{ }^{b} \text { ) }\end{array}$ & $\begin{array}{l}\text { 1953: } 300 \text { million US\$; affected: } 300 \text { 000; deaths: } 2000 \\
\text { 1992: } 28 \text { million US\$; affected: -; deaths: } 0 \\
\text { 1993: } 53 \text { million US\$; affected: } 13000 \text {; deaths: } 1 \\
\text { 1998: } 530 \text { million US\$; affected: } 2000 \text {; deaths: } 0\end{array}$ & $\begin{array}{l}\text { 1978: } 330 \text { million US\$; affected: -; deaths: } 2 \\
\text { 1983: - million US\$; affected: 12; deaths: } 0 \\
\text { 1988: - million US\$; affected: 3500; deaths: } 6 \\
\text { 1991: } 56 \text { million US\$; affected: -; deaths: } 5 \\
\text { 1992: } 30 \text { million US\$; affected: -; deaths: } 0 \\
\text { 1993: } 600 \text { million US\$; affected: } 100 \text { 000; deaths: } 5 \\
\text { 1994: } 394 \text { million US\$; affected: -; deaths: } 2 \\
\text { 1997: } 360 \text { million US\$; affected: 5200; deaths: } 0 \\
\text { 1999: } 430 \text { million US\$; affected: } 100000 \text {; deaths: } 7 \\
\text { 2002: } 11600 \text { million US\$; affected people: } 330108 \text {; } \\
\text { deaths: } 27 \\
\text { 2005: } 220 \text { million US\$; affected: 450; deaths: } 1 \\
\text { 2006: - million US\$; affected: 1000; deaths: } 0 \\
\text { 2007: - million US\$; affected: -; deaths: } 1 \\
\text { 2009: } 20 \text { million US\$; affected: -; deaths: } 0 \\
\text { 2010: - million US\$; affected: -; deaths: } 3 \\
\text { 2011: - million US\$; affected: -; deaths: } 4\end{array}$ \\
\hline
\end{tabular}

Notes: ${ }^{a}$ The German average flood damage to residential buildings is estimated using data that are based on actual flood events, while this amount for the Netherlands has been estimated using a flood risk model. ${ }^{b}$ Extracted on 23 November 2011 from "EM-DAT": The OFDA/CRED International Disaster Database www.emdat.be - Université Catholique de Louvain - Brussels - Belgium; damage figures in US\$ are shown true to the year of the event, "-" indicates that no data are available.

between the different levels of government about who should pay the administrative costs, while ad hoc government compensation was regarded as an attractive means by politicians to gain support by the public and attract votes (Schwarze and Wagner, 2007). Nevertheless, the compulsory natural disaster insurance remains an option for the future. Research on flood insurance is needed for the development of efficient risk mitigation and adaptation strategies in Germany.

\subsection{Financial arrangements for flood damage in the Netherlands}

In general, insurance coverage for flood damage is excluded from the usual property insurance policies in the Netherlands. After the major North Sea storm surge in 1953 many Dutch insurance companies cancelled their flood insurance policies, because the risks were considered to be too large and impossible to insure in a private market. The predecessor of the Dutch Insurers Union (Verbond van Verzekeraars) issued a binding decree in 1955 stating that its members were not allowed to insure flood risk. In 1998 this binding decree was changed into advice in order to comply with European competition laws (Faure, 2006). Nevertheless, at present there are no major Dutch insurers that offer an insurance policy against flood damage (Botzen et al., 2010). ${ }^{3}$

\footnotetext{
${ }^{3}$ Except for damage to cars, which motor-hull insurance policies cover (Botzen et al., 2010).
}

An exception is a "catastrophe risk" insurance policy that has been available since September 2012 and provides coverage against terrorism risk, earthquakes and flooding. However, this insurance product will not result in a broad insurance coverage for flood risk in the Netherlands because it provides a rather limited coverage, it is only available for a limited number of households because of a lack of insurance capacity, and its premium is too high to attract sufficient demand. Flood risks in a small country such as the Netherlands are highly correlated, which implies that insurers could face very large losses because of a single flood event that, moreover, may be beyond the capacity of the insurance sector to cover. Part of the extreme risks could be reinsured or spread on financial markets through alternative risk transfer instruments, but this comes at a relatively high cost which consumers may be unwilling to pay.

The government may partly compensate flood damage suffered by households via the "Calamities and Compensation Act" (WTS). This law enables the government to provide damage relief and operates as an ex-post compensation scheme for which no funds have been collected ex ante. Compensation of damage through the WTS can be provided if the government declares a flood as a major disaster, which is a political decision. It is, therefore, uncertain whether households receive compensation for flood damage, and nopredefined rules determine how much of the actual damage suffered the government will compensate. This arrangement 


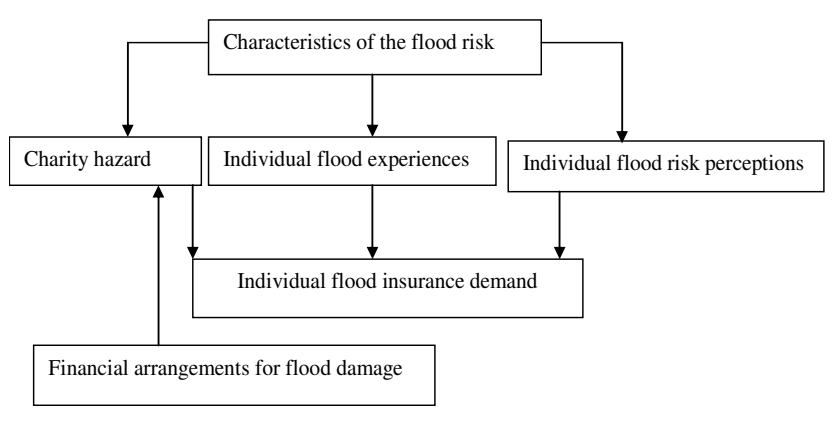

Fig. 1. Theoretical framework of factors of influence on individual flood insurance demand that are examined in this study.

for compensating flood damage may be regarded as inefficient, because it provides few incentives for households to limit their risk, especially if individuals expect that the government will compensate any flood damage irrespective of the risks that they take.

Private flood insurance with risk-based premiums could be beneficial for households by providing more financial security (Botzen and van den Bergh, 2009), and better incentives to households to limit risk (Botzen et al., 2009a). However, introducing a (purely) private flood insurance arrangement in the Netherlands is complicated by the low-probability, high-impact nature of the flood risk. Botzen and van den Bergh (2008) propose introducing a public-private partnership to insure flood damage in the Netherlands, with a role for the government as reinsurer to overcome difficulties with insuring correlated and potentially catastrophic flood risks. Similar schemes have been proposed to insure natural disaster risks in the USA (Kunreuther, 2006; Michel-Kerjan, 2010). Research on household demand for flood insurance provides relevant information for assessing the marketability of insurance against flood damage in the Netherlands.

\section{Theoretical framework}

Figure 1 shows a schematic overview of the focus of this research. This study examines how flood insurance demand differs between the Netherlands and Germany, within the context of the differences in flood risks between these two countries. The low-probability high-impact flood risk in the Netherlands compared with the relatively mediumprobability medium-impact flood risk in Germany is likely to affect flood insurance demand. Differences in general flood risk affect individual flood insurance demand via different influences on demand which are related to, but not the same as, the general country flood risk characteristics. Such influences are for instance charity hazard, individual flood experiences and individual risk perceptions, as we will explain below.

\subsection{Flood risk perceptions}

In evaluating hazards, people commonly rely on intuitive risk judgments, called risk perceptions, which often differ considerably from expert assessments (Slovic, 1987, 2000). Individual perceptions of hazards are often regarded as important factors behind decision-making under risk with respect to insurance purchases and the undertaking of self-protective measures (Burn, 1999; Flynn et al., 1999). The importance of risk perceptions in individual decision-making is rooted in subjective expected utility theory (Savage, 1954). This theory postulates that individuals form a subjective probability of uncertain outcomes (e.g. of a flood and the damage it may cause), and subsequently decide whether to take any action to reduce this risk, for example, by purchasing insurance. A low perception of flood risks by individuals may translate into a low demand for flood insurance (Kunreuther, 1984). Although flood risks differ within both countries, the flood frequency of the Dutch sample area of the survey is lower than the sample area in Germany. Flood risk perceptions may be lower in a country with a very low frequency of flooding, like the Netherlands, than in Germany where flood frequencies are higher, which could result in a lower demand for flood insurance by Dutch households.

\subsection{Flood experience}

Several studies that examined the influence of disaster experience on insurance demand and mitigation behaviour find that individuals commonly have a higher flood insurance demand after recent experiences of flooding (Browne and Hoyt, 2000; Kriesel and Landry, 2004; Zahran et al., 2009; MichelKerjan and Kousky, 2010). This can be related to the "availability heuristic" in judging natural hazard risk, which implies that individuals judge an event as risky if it is easy to imagine or recall (Kahneman et al., 1982). For example, individuals who have experienced a disaster may find it easier to imagine that the disaster happens again in the future and, therefore, have a higher perceived risk and demand for insurance against the risk than individuals without this experience. Individuals are more likely to experience flooding in areas with a higher flood frequency, which is expected to increase flood insurance demand in such areas. In Germany floods occurred in 2002, 2005, 2006, 2007, 2009, 2010 and 2011, which could have increased demand for flood insurance, while damaging floods in the Netherlands may have been too long ago, i.e. more than $10 \mathrm{yr}$ (Table 1) to significantly affect current demand.

\subsection{Charity hazard}

Individuals may decide not to purchase flood insurance because they anticipate that the government will compensate part of the damage that they may suffer because of floods, which has been called the charity hazard (Raschky and 
Weck-Hanneman, 2007). Studies in several countries have shown that politicians use the provision of assistance after disasters by compensating damage for gaining political support (Besley and Burgess, 2002; Mustafa, 2003; Garrett and Sobel, 2003). Even though there is no guarantee that government compensation of disaster damage will be efficiently provided or that it will be distributed to households who are most in need for assistance, disaster assistance is often accompanied with broad nationwide media coverage which may create household expectations that the government will also compensate their damage if they were to be affected by a flood in the future. The theoretical prediction is that government compensation of disaster damage reduces insurance demand (Lewis and Nickerson, 1989), but the few empirical studies that exist on this topic have mixed results: namely, some studies have found that the charity hazard reduces demand for natural disaster insurance, while others found no significant effect of the charity hazard (Raschky and WeckHanneman, 2007). Charity hazard may be an issue in both Germany and the Netherlands because the governments have stepped in to compensate flood damage in both countries. The charity hazard may be influenced by the financial arrangement that is in place for compensation of flood damage, as Fig. 1 shows. For example, the absence of private flood insurance in the Netherlands may have created high expectations that the government will step in to compensate flood damage. On the other hand, it may be expected that disaster assistance has a larger effect on the crowding out of insurance demand in areas where floods are more frequent (Germany) than in areas with less frequent floods (the Netherlands), because beliefs that the government will compensate damage may be stronger in areas where the government has already done so repeatedly in the past.

\subsection{Main hypotheses}

This study tests the following four main hypotheses:

H1: willingness to pay (WTP) for insurance against medium-probability medium-impact flood risk in Germany is higher than WTP for insurance against lowprobability high-impact risk in the Netherlands;

$\mathrm{H} 2$ : recent flood experience in Germany has increased demand for flood insurance more than in the Netherlands where damaging floods may have happened too long ago to significantly affect current demand;

H3: demand for flood insurance is positively related to individual flood risk perceptions. These flood risk perceptions are higher in Germany than in the Netherlands;

H4: governmental disaster assistance has a larger effect on the crowding out of insurance demand in areas where floods are more frequent (Germany) than in areas with less frequent floods (the Netherlands).

\section{Collection of data on flood insurance demand and statistical methods}

\subsection{Data collection in Germany}

After the flood events in 2002, 2005 and 2006 in the Elbe and Danube catchments in Germany (see Fig. 2), affected private households were interviewed by telephone in 2003 and 2006 (Thieken et al., 2005, 2007; Kreibich and Thieken, 2009; Kreibich et al., 2005, 2011). With the help of flood maps derived from radar satellite data (DLR, Center for Satellite Based Crisis information, www.zki.caf. dlr.de), and official data (e.g. reports, press releases) lists of all affected streets were comprised. Using these lists, building-specific, random samples of households were generated. The computer-aided telephone interviews were undertaken with the VOXCO software package (www.voxco.com). The SOKO institute for social research and communication (www.soko-institut.de) interviewed private households in April and May 2003. The Explorare institute for marketing research (www.explorare.de) undertook the interviews in November and December 2006. Since both surveys were undertaken anonymously and independently from each other, the possible percentage of people who were interviewed twice is unknown. About $25 \%$ of the interviewees in 2006 stated that they had been also affected by the 2002 flood event. In the first survey, 1697 interviews with private households were completed, and 461 interviews were completed in the second survey. Only households who had suffered economic damage to their building or contents were interviewed. In each household the individual with the best knowledge of the flood damage was always questioned. The complete sample containing data from both surveys has slightly more female $(53 \%)$ than male respondents. The median household size is 2 people, at least one child lives in $24 \%$ of the households. On average respondents are $52 \mathrm{yr}$ old, $16 \%$ of the respondents have a university degree as highest education level. The average after-tax household income is the answer category "between $€ 1500$ and $€ 2000$ per month".

Both questionnaires contained more than 150 questions, which addressed the following topics: flood experience, flood impact (e.g. water level and contamination), flood damage and damage compensation, precautionary and emergency measures, as well as socio-economic characteristics. For instance, the interviewed households were asked whether they had flood insurance before the flood event happened, whether they purchased flood insurance directly after the flood event, whether they planned to purchase flood insurance within the next six months after the interview or whether contracting insurance was not intended or not possible. Thieken et al. (2005) provide a detailed description of the survey in 2003 and the processing of data. In the second survey, questions about financial flood loss compensation and natural hazard insurance were added to the questionnaire, such as a question on the maximum amount of money people were willing to 


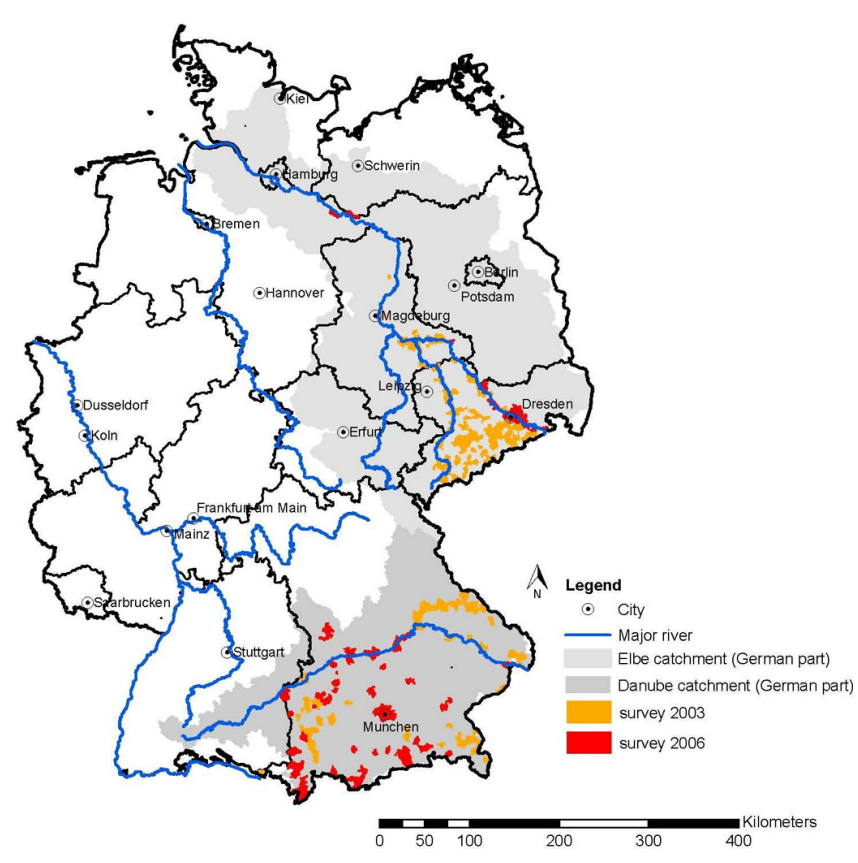

Fig. 2. Sample area of the survey in the Elbe (Eastern Germany) and Danube (Western Germany) catchments in Germany (data sources: rivers and administrative boarders: DLM1000 of BKG (2001); cities: Esri, DeLorme Publishing Company, inc.; catchment areas: CCM2 data of JRC, Vogt et al. 2007).

spend on natural hazards insurance. The format of this question corresponds to a commonly used open-ended contingent valuation question which asks for hypothetical intentions to purchase flood insurance and WTP which are related to, but not perfectly correlated with, actual demand and consumer behaviour (Mitchell and Carson, 1989). Since the German interviewees all live in flood-prone areas and were recently affected by a flood event, we expect that the flood hazard will play the dominant role when deciding on the amount of money to spend on natural hazards insurance. Thus, the questions in the Dutch and the German survey are comparable, and we don't distinguish any more between natural hazard insurance and flood insurance in the remainder of this article.

\subsection{Data collection in the Netherlands}

In the Netherlands a stated preference survey has been conducted to obtain insights into homeowner's perception of flood risk and their willingness to pay for flood insurance. The survey took place in December 2007 and was conducted over the Internet using Sawtooth CBC software. Respondents were selected from the consumer panel of Multiscope ${ }^{4}$ and contacted by email. This email did not specify the topic of the survey, in order to prevent selection bias. The sample consists of homeowners who live in the river delta of the Nether-

\footnotetext{
${ }^{4}$ For more information see www.multiscope.nl.
}

lands with a flood safety standard of once in $1250 \mathrm{yr}$ (the areas indicated with the letter " $D$ " in Fig. 3). The resulting total number of completed questionnaires is 982 . The survey was removed from the Internet once the desired number of respondents was reached. ${ }^{5}$

The sample was set up to be representative for Dutch homeowners until an age of $60 \mathrm{yr}$. The survey elicits demand for flood insurance that covers damage to both home contents and buildings, which is why the sample excludes tenants since they do not bear the costs of flood damage to their homes. Respondents who live in apartments higher than the first floor and respondents who live outside the sample area were removed from the data. Our sample has slightly more male $(58 \%)$ than female respondents. Approximately $50 \%$ of the respondents have at least one child who still lives at home, and $39 \%$ have a Bachelor's or Master's degree as highest education level. On average respondents are $46 \mathrm{yr}$ old. The average after-tax household income is the answer category "between $€ 2501$ and $€ 3000$ per month", which is close to the average after-tax income of a household who owns a house in the Netherlands, namely $€ 3025$ per month (Statistics Netherlands, 2008).

Botzen et al. (2008) provide a detailed explanation of the survey, which was structured as follows. It starts with several questions on the experience of the respondent with flooding and evacuation because of flood threats. Although the major storm surge flood in 1953 has for most respondents been too long ago to have experienced it, smaller flood events occurred in the 1990s which almost resulted in large-scale flooding. For example, in 1995 more than 200000 people in our sample area were evacuated because of flood threats. Subsequently, perceptions of the flood risk of homeowners are elicited using questions on the expected damage, probability and return period of flooding. The next part of the survey assesses individuals' willingness to pay for flood insurance (Botzen and van den Bergh, 2012a, b). The insurance product valued completely covers damage to both buildings and home contents caused by river flooding. Demand for flood insurance is elicited by means of the contingent valuation method. Respondents were asked if they are in principle interested in purchasing flood insurance, and if they answer yes, how much they are at maximum willing to pay for flood insurance which provides full coverage. A slight difference with the Germany survey is that respondents were provided with a payment card in the Dutch survey on which several WTP values were shown, as a visual aid to facilitate answer-

\footnotetext{
5 The use of the consumer panel of Multiscope does not allow us to calculate the exact response rate to our survey since the survey was removed from the Internet once a pre-specified quota of completed questionnaires was reached. On average, response rates of the consumer panel are well above $20 \%$ (www.mutiscope.nl).
} 


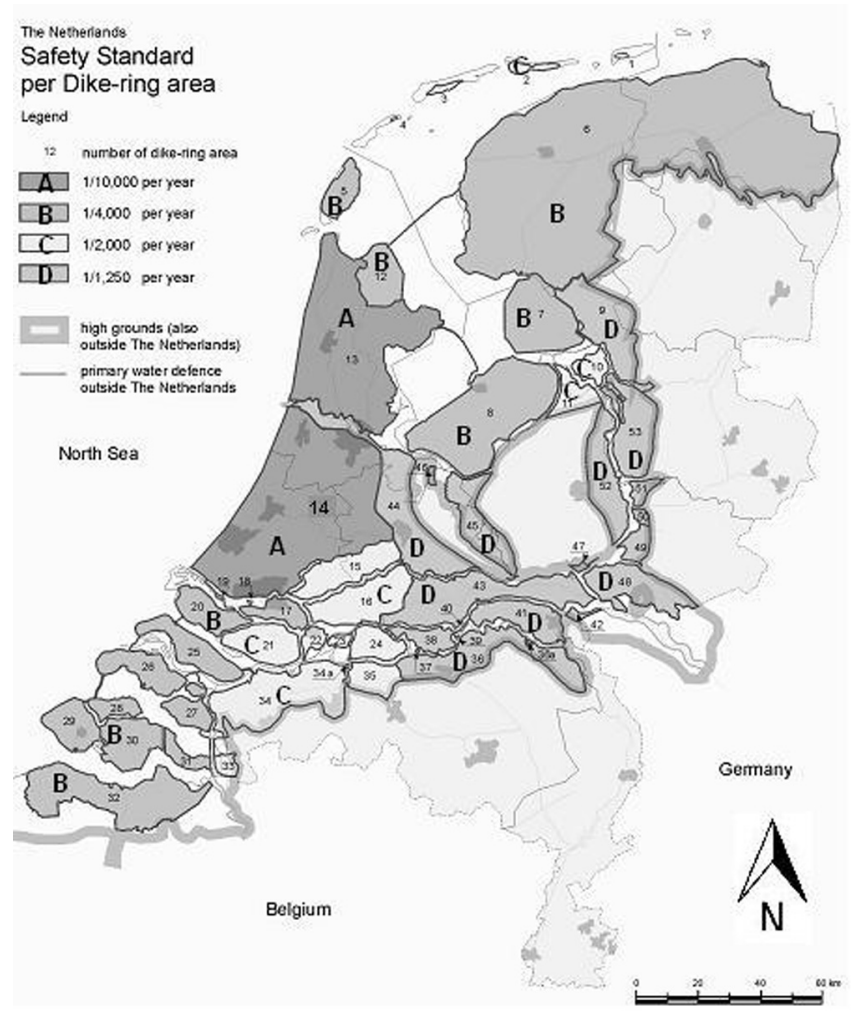

Fig. 3. Safety standards of dike-ring areas in the Netherlands. The letters A to D are used to indicate the safety standards between $1 / 10000$ per year and 1/1250 per year. Source: TAW (2000).

ing the contingent valuation question. ${ }^{6}$ Nevertheless, we regard the results between the Dutch and German as comparable because both surveys explicitly stated that respondents could answer any amount of money that respondents were willing to spend on the insurance.

\subsection{Applied statistical methods}

Descriptive statistics of the answers to the surveys will be provided in Sect. 5 in order to obtain insights into demand for flood insurance in Germany and the Netherlands. A large part of the German and Dutch data are not normally distributed and, therefore, both the mean and the median answers are given. Moreover, results of statistical tests will be provided to examine relations between flood insurance demand and other variables which are expected to be of influence on demand. Statistical analyses are undertaken with the statistical software package SPSS for Windows (Version 11.5.1.). To test significant differences between independent groups of data, different methods are applied, depending on the scale of the data. Nominal-scaled data are tested using Pearson's $\mathrm{Chi}^{2}$ test. For ordinal-, interval- or ratio-scaled data the Mann-

6 These fixed categories were carefully derived from answers to open-ended questions during the pre-tests of the survey, using a method described in Rowe et al. (1996).
Whitney- $U$ test is used for two independent groups of data, and the Kruskal-Wallis $\mathrm{H}$ test is applied for three or more independent groups (Norušis, 2002). For correlation analysis Cramér's V is used in analyses of only nominal-scaled data. For data of other scales, Spearman's correlation coefficient $\rho$ is calculated with pair-wise data exclusion. For the statistical test and correlation measures a significance level of $p \leq 0.05$ is used. Due to differences in historical development of flood insurance in Western and Eastern Germany, some of the analyses are done separately for both parts of Germany.

\section{Comparison of household demand for flood insurance between Germany and the Netherlands}

\subsection{Willingness to pay for flood insurance}

Based on the theoretical framework in Sect. 3, we hypothesise that the willingness to pay (WTP) for flood insurance, i.e. the amount of money people are willing to spend on flood insurance, is higher in Germany, where flood risk is characterised as a medium-probability and medium-impact risk, than in the Netherlands, where flood risk is characterised as a low-probability high-impact risk $(\mathrm{H} 1)$.

Table 2 shows the results of the question about willingness to pay for flood insurance by Dutch homeowners under the scenario in which compensation for flood damage may be obtained from the government. The WTP is an indicator of the mean of willingness to pay for flood insurance by all homeowners and is the relevant measurement for policy makers who are interested in the welfare effects of introducing flood insurance. About $70 \%$ of the respondents have a zero WTP value under this scenario. On average, the WTP is $€ 2.80$ per month. The conditional willingness to pay (CWTP) is the mean willingness to pay by homeowners who are willing to pay a positive amount for flood insurance. It indicates potential revenue per policy. On average, the CWTP is $€ 10$, which is above the mean expected flood loss per insurance policy, which is equal to $€ 4.7$ per month in price levels at the time of the survey. ${ }^{7}$

In the second German survey that was conducted after the flood events in 2005 and 2006, private households were asked how much money they would be willing to spend per month for natural hazard insurance, including flood insurance. About $59 \%$ of the respondents have a zero WTP value. The mean WTP and CWTP of German households are with $€ 26$ and $€ 65$ considerably higher than in the Netherlands (see Table 2). These findings confirm our hypothesis that WTP for insurance against medium-probability medium-impact flood risk in Germany is higher than WTP for insurance against low-probability high-impact flood risk in the Netherlands (H1).

\footnotetext{
7 This expected value of the damage per household in the 1-in1250 norm dike-ring areas is based on flood damage models and computed as described in Botzen and van den Bergh (2009).
} 
Table 2. Average willingness to pay (WTP) and conditional willingness to pay (CWTP) for flood insurance per month of Dutch and German private households.

\begin{tabular}{|c|c|c|c|c|}
\hline & \multicolumn{2}{|c|}{ The Netherlands } & \multicolumn{2}{|c|}{ Germany } \\
\hline & WTP & CWTP & WTP & CWTP \\
\hline$N$ & 507 & 297 & 310 & 126 \\
\hline Mean & $€ 2.80$ & $€ 10.07$ & $€ 26.26$ & $€ 64.62$ \\
\hline Standard deviation & $€ 7.28$ & $€ 10.90$ & $€ 56.15$ & $€ 72.77$ \\
\hline Minimum & $€ 0$ & $€ 1$ & $€ 0$ & $€ 3$ \\
\hline 25 th percentile & $€ 0$ & $€ 4$ & $€ 0$ & $€ 20$ \\
\hline 50th percentile & $€ 0$ & $€ 8$ & $€ 0$ & $€ 50$ \\
\hline 75th percentile & $€ 2$ & $€ 10$ & $€ 30$ & $€ 100$ \\
\hline Maximum & $€ 80$ & $€ 80$ & $€ 500$ & $€ 500$ \\
\hline
\end{tabular}

\subsection{Flood experience}

We hypothesise that recent flood experience in Germany has increased demand for flood insurance more than in the Netherlands, where damaging floods may have happened too long ago to significantly affect current demand (H2). To test this hypothesis we estimate in both countries the influence of the experience of flooding and flood damage or evacuation due to flooding on demand for flood insurance.

The influence of experience with flooding on insurance demand is analysed with two similar questions in the German and Dutch surveys. In the German survey households were asked whether they experienced a flood before the actual flood event and whether they purchased flood insurance before the actual flood event. Also they were asked whether they were evacuated during the actual flood event and whether they plan to purchase flood insurance in the near future. In the Netherlands households were asked whether they experienced a flood and whether they were evacuated because of an actual flood threat.

For the Netherlands it is examined whether a relation between experience with flooding and a respondents' general willingness to purchase flood insurance ("yes" or "no") can be observed. Approximately $20 \%$ of the respondents indicated that they experienced a flood at least once during their life. The Pearson's $\mathrm{Chi}^{2}$ test shows that no significant difference exists between individuals with and without experience of flooding and their willingness to purchase flood insurance. It is, furthermore, estimated whether a relation exists between experience with evacuation because of a threat of flooding and the willingness to purchase flood insurance. Approximately $9 \%$ of the respondents indicated that they had been evacuated because of a flood threat. The Pearson's $\mathrm{Chi}^{2}$ test indicates that a significant relation exists ( $p$ value $<0.01$ ) between the experience with evacuation and the willingness to purchase flood insurance. In particular, $49 \%$ of the homeowners who were evacuated because of flooding were willing to pay for flood insurance compared with $31 \%$ of the homeowners who were never evacuated. Although evacuation is not directly related to flood insurance, experience with evacuation because of flood threats can make the flood risk more salient for people, which increases their demand for (financial) protection against floods.

Similar results are observed for the relation between the WTP for flood insurance and experience with floods in the Netherlands. A low Spearman's Rho correlation statistic of 0.06 is observed between the WTP for flood insurance and the experience with flooding; the WTP is significantly higher among households with flood experience $(p$ value $<0.05$ ). The correlation between the WTP and experience with evacuation is considerably larger (0.14) and significant at the $1 \%$ level.

Table 3 compares the influence of these experiences on flood insurance demand in Germany. Due to the differences in insurance history, we split our results up into Eastern and Western Germany. In Eastern Germany, only $19 \%$ of the interviewed people had experienced a flood before and in Western Germany $45 \%$ had this experience. From the people in Eastern Germany who had flood experience $(n=247)$, $61 \%$ purchased flood insurance (Table 3). At $49 \%$, the percentage of insured households in the group of people without flood experience is much lower. A $\mathrm{Chi}^{2}$-Test shows that these differences in Eastern Germany are significant ( $p$ value $<0.01 \%$ ). However, a correlation analysis shows that the correlation between the experience with flooding and the purchase of flood insurance is low (Cramér's $V=0.1$ ). In Western Germany there is no significant difference between the demand for flood insurance between individuals who have and have not experienced a flood; in both groups the insurance density is about $20 \%$ (Table 3). Concerning the WTP for flood insurance, neither for Eastern nor for Western Germany was a significant influence of flood experience found.

Next, it is estimated whether a relation exists between experience with evacuation due to flooding and the willingness to purchase flood insurance in the near future. In Eastern Germany $54 \%(n=258)$ and in Western Germany $10 \%(n=54)$ of the respondents were evacuated. The $\mathrm{Chi}^{2}$ Test shows a significant relation only for Eastern Germany ( $p$ value $<0.05 \%$ ), with a low Cramér's V correlation of 0.1 . From the respondents in Eastern Germany who experienced evacuation $24 \%$ planned to purchase insurance, in comparison with only $15 \%$ of the respondents without evacuation experience who planned to do so. The effects of evacuation on the level of WTP are insignificant.

Next, it is examined for Germany whether the amount of damage to buildings or building inventories influences the willingness to purchase flood insurance in the near future. For both loss categories - buildings and building inventory a Mann-Whitney- $U$ test revealed significant differences for a $1 \%$ significance level. Private households who planned to purchase flood insurance within the next 6 months suffered (due to the current flood) a mean building loss of $€ 43424$, 
Table 3. Cross tabulation (in absolute values and row percentage) of private households in Eastern and Western Germany, who experienced, and who did not experience, a flood and whether or not they purchased flood insurance before the flood event.

\begin{tabular}{lcrr}
\hline & \multicolumn{3}{c}{ Purchased flood insurance before the flood } \\
\hline Part of Germany & Experience with flooding & No & Yes \\
\hline Eastern Germany & No & $545(51 \%)$ & $516(49 \%)$ \\
\multirow{3}{*}{ Western Germany } & Yes & $97(39 \%)$ & $150(61 \%)$ \\
& No & $341(79 \%)$ & $92(21 \%)$ \\
& Yes & $276(78 \%)$ & $77(22 \%)$ \\
\hline
\end{tabular}

whereas private households who did not plan to purchase insurance, or for whom purchasing insurance was not possible, only had a mean loss of $€ 24670$.

Furthermore, it is examined whether the amount of occurred loss influenced the amount of money people would spend on natural hazard insurance. A significant correlation of 0.22 (Spearman's Rho, pair-wise data exclusion, significance level of $p<0.01 \%$ ) was found between building loss and the amount of money private households would spend on natural hazard insurance. The correlation is higher for inventory loss, namely 0.31 using the same test. When building losses were lower than $€ 5000$, only $4 \%$ of the private households were willing to spend more than $€ 100$ per month on natural hazard insurance, whereas $25 \%$ were willing to pay this amount of money when they suffered building losses of more than $€ 50000$ (see Fig. 4). A similar analysis is not conducted for the Netherlands because almost none of the respondents of the Dutch survey has ever experienced flood damage, which is due to the rarity of damaging flood events.

In summary, the results of the influence of flood experience on flood insurance demand are mixed. Flood experience has no significant influence on demand for flood insurance in the Netherlands, while more people purchased flood insurance when they experienced a flood before in Eastern Germany, but not in Western Germany. Experience with evacuation has a positive effect on flood insurance in the Netherlands as well as in Eastern Germany, but not in Western Germany. It is difficult to explain why flood experiences have different impacts on flood insurance demand in these different regions. The correlations between flood experience and willingness to purchase flood insurance are low in both Germany and the Netherlands. In contrast, the previous flood damage correlates strongly with WTP for flood insurance in Germany, while this effect cannot be observed in the Netherlands because hardly any Dutch respondents actually suffered flood damage. Overall these findings are consistent with research showing that more intense experiences with a hazard (such as evacuation or damage) increases protective behaviour (e.g. Riad et al., 1999). Concerning our hypothesis (H2) we can conclude that such intense experiences, and in particular experience with damage, which are more likely to occur in Germany than in the Netherlands, can partly explain the higher level of WTP for flood insurance in Ger-

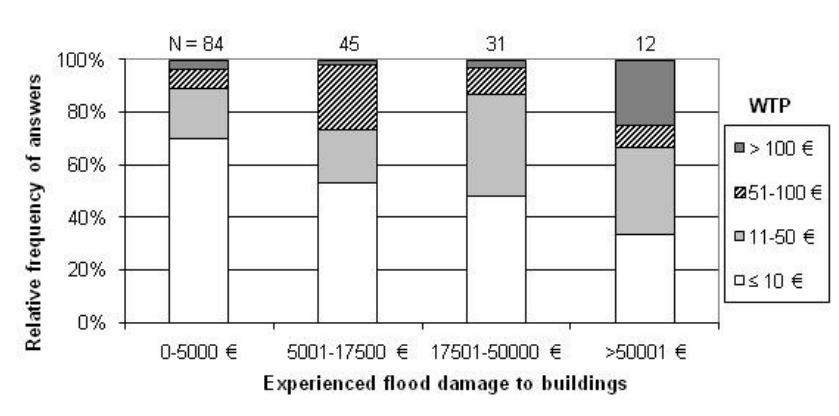

Fig. 4. Experienced flood damage to buildings in Germany and the frequency of answers of willingness to pay (WTP) for flood insurance by private households.

many, while other explanations such as flood risk perceptions (see Sect. 5.3) and the charity hazard (see Sect. 5.4) also contribute to this higher WTP.

\subsection{Flood risk perceptions}

As outlined in the theoretical framework in Sect. 3, we hypothesise that flood risk perceptions are lower in a country with a very low frequency of flooding like the Netherlands than in Germany where flood frequencies are higher, which results in a lower demand for flood insurance by Dutch households (H3).

The perception of the flood probability by respondents is similarly measured in both surveys on a scale from 1 to 6 . Respondents were asked to rate the probability of a flood occurring in their living area on a qualitative scale with the options: (1) "I do not have any flood risks"; (2) "very low"; (3) "low"; (4) "not low/not high"; (5) "high"; (6) "very high"; and (7) "don't know". The answers to this question are shown in Table 4 from which it is apparent that the large majority of respondents $(>70 \%)$ perceives that he/she has a low or very low flood probability or faces no flood risk at all. Next, it is examined whether the respondents' perception of the flood probability influences their willingness to purchase flood insurance. The Pearson's $\mathrm{Chi}^{2}$ test is applied because the perceived flood probability is an ordinal variable with more than two categories. Results of this test for the Dutch data indicate that the perception of the flood probability significantly 
Table 4. Respondents' perceived flood probability (in \% of total respondents) and corresponding mean willingness to pay for flood insurance (in $€$ per month).

\begin{tabular}{lrrrr}
\hline Perceived flood probability & The Netherlands & The Netherlands \\
$N=932$ & $\mathrm{~N}=932$ & $\begin{array}{r}\text { Germany } \\
\mathrm{N}=299\end{array}$ & $\begin{array}{r}\text { Germany } \\
\mathrm{N}=299\end{array}$ \\
\hline (1) I do not have any flood risks & $10.5 \%$ & $€ 0.96$ & $6.7 \%$ & $€ 13.15$ \\
(2) very low & $30.7 \%$ & $€ 1.71$ & $11.0 \%$ & $€ 17.12$ \\
(3) low & $30.8 \%$ & $€ 3.51$ & $16.1 \%$ & $€ 23.15$ \\
(4) not low/not high & $19.3 \%$ & $€ 4.42$ & $11.4 \%$ & $€ 20.00$ \\
(5) high & $7.4 \%$ & $€ 8.76$ & $13.7 \%$ & $€ 32.56$ \\
(6) very high & $0.7 \%$ & $€ 11.29$ & $41.1 \%$ & $€ 32.75$ \\
\hline
\end{tabular}

determines the willingness to purchase flood insurance (at the $1 \%$ level). The willingness to insure is considerably larger for respondents with an elevated risk perception $(76 \%$ and $71 \%$ for categories 5 and 6) compared with respondents with a low risk perception (12\% and $17 \%$ for categories 1 and 2). Moreover, a high Spearman's Rho correlation statistic (0.37) is observed between the WTP for flood insurance and the perceived flood probability that is highly significant (at the $1 \%$ level). The relation between the WTP for flood insurance and the perceived flood probability is shown in Table 4, which shows that respondents with a high perception of the flood probability (categories 5 and 6) have a much higher WTP than respondents with a low risk perception (categories 1, 2 and 3). Results of statistical analyses of relations between flood risk perceptions in the Netherlands and indicators of actual flood risk have been reported by Botzen et al. (2009b) who show that these flood risk perceptions are at least partly related to actual flood risk.

German interviewees were asked to estimate the probability of a future flooding of their house or flat on a scale from 1 (very low probability) to 6 (very high probability) which has a similar scale as was used in the Dutch survey. The results in Table 4 show that flood risk perceptions in Germany are substantially higher than in the Netherlands. More than $50 \%$ of the respondents perceive their flood probability as high or very high. The results were compared with the amount of money people were willing to spend on natural hazard insurance. A Spearman's Rho correlation coefficient of 0.2 $(p<0.01 \%)$ revealed a highly significant positive correlation of the perceived flood probability with the WTP. Except for the flood probability category 4 , the mean WTP increases with increasing estimates for flood probabilities (Table 4).

In order to arrive at an indicator of expected flood losses, the Dutch survey asked how much total damage households expect to suffer once a flood occurs. Average expected flood damage is $€ 70000$ (Botzen et al., 2009b). It is examined whether homeowners who indicate that they expect to suffer larger flood damage are more likely to purchase flood insurance than homeowners who expect to suffer less flood damage. The Mann-Whitney- $U$ test indicates that significant differences exist between the amount of flood damage

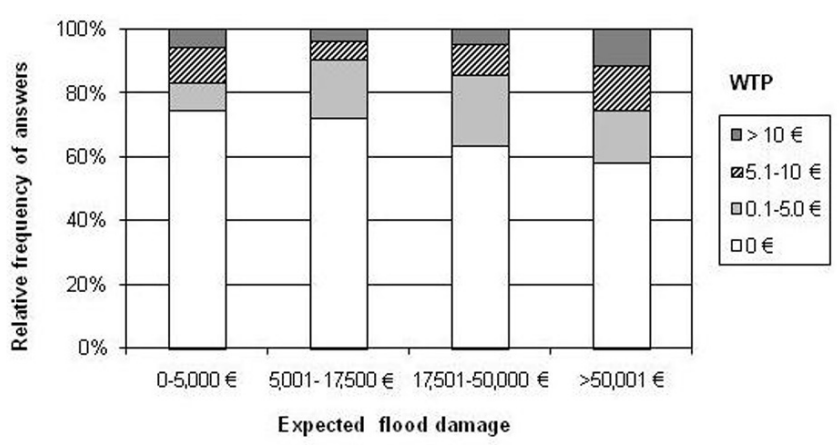

Fig. 5. Expected flood damage in the Netherlands and the corresponding frequency of answers of willingness to pay (WTP) for flood insurance by private households.

individuals expect and their willingness to purchase flood insurance ( $p$ value $<0.01$ ). Households willing to purchase flood insurance expect to suffer on average flood damage of $€ 108000$, while this is $€ 51000$ for households who do not want to purchase flood insurance. A significant Spearman's Rho correlation of 0.2 can be observed between the amount households willing to pay for flood insurance and the amount of damage they expect to suffer as a result of flooding ( $p$ value $<0.01$ ). In particular, Fig. 5 indicates that a positive relation exists between the expectations of suffering very large damage ( $>€ 50000)$ and the largest category of WTP for flood insurance $(>€ 10)$. These results are consistent with the observed relation between past flood losses and flood insurance demand in Germany (see Sect. 5.2).

In summary, the findings support our hypothesis that the demand for flood insurance is strongly positively related to individual flood risk perceptions (H3). Flood risk perceptions are higher in Germany than in the Netherlands, which is consistent with the actual differences in flood frequencies, and contributes to the higher WTP for flood insurance in Germany.

\subsection{Charity hazard}

Our fourth hypothesis is that governmental disaster assistance has a larger effect on the crowding out of insurance 
Table 5. Comparison of the WTP for flood insurance by households who received or did not receive governmental compensation for flood damage in Germany and Dutch private households, who can obtain or cannot obtain governmental compensation for flood damage.

\begin{tabular}{lccllc}
\hline & \multicolumn{2}{c}{ Germany } & & \multicolumn{2}{c}{ The Netherlands } \\
\cline { 2 - 3 } \cline { 5 - 6 } & $\begin{array}{c}\text { Received financial governmental } \\
\text { relief after recent floods }\end{array}$ & & $\begin{array}{c}\text { Availability of compensation } \\
\text { from the government }\end{array}$ \\
\cline { 2 - 3 } \cline { 6 - 7 } & No & Yes & & No & Yes \\
\hline$N$ & 111 & 33 & & 507 & 419 \\
Mean & $€ 57$ & $€ 55$ & & $€ 4$ & $€ 2$ \\
\hline 25th percentile & $€ 15$ & $€ 20$ & & $€ 0$ & $€ 0$ \\
50th percentile & $€ 30$ & $€ 40$ & & $€ 0$ & $€ 0$ \\
75th percentile & $€ 80$ & $€ 65$ & & $€ 4$ & $€ 2$ \\
95th percentile & $€ 200$ & $€ 195$ & & $€ 20$ & $€ 15$ \\
\hline
\end{tabular}

demand in areas where floods are more frequent (Germany) than in areas with less frequent floods (the Netherlands), because expectations that the government will compensate damage may be stronger in areas where the government has already done so repeatedly in the past (H4).

In the German survey, two separate questions asked whether households obtained financial governmental aid after recent flood events and whether they plan to purchase flood insurance in the near future. A comparison of the answers to these questions indicates whether the receipt of governmental aid influences their demand for flood insurance. A $\mathrm{Chi}^{2}$-Test reveals no significant difference between people who received or did not receive governmental compensation for flood damage with respect to their intention to purchase flood insurance.

In addition, it is examined using the second German survey whether the receipt of governmental flood compensation in the past has an influence on the amount of money people are willing to spend on flood insurance. On average, people who did not obtain governmental flood aid were willing to spend $€ 2$ more per month on flood insurance than people who did obtain governmental aid (Table 5). However, this difference is not statistically significant.

The Dutch survey elicited flood insurance demand with different questionnaire versions of scenarios explaining that partial compensation for flood damage is available from the government and a version explaining that such compensation is no longer granted, but that instead only private insurance can be purchased. The result shows that approximately $28 \%$ of the respondents are willing to pay for flood insurance if damage relief is available, while this proportion is $36 \%$ if damage relief is no longer granted. The Pearson's $\mathrm{Chi}^{2}$ test indicates that this difference is significant ( $p$ value $<0.01$ ).

On average, the WTP for flood insurance is larger in the Netherlands if the government does not provide compensation of flood damage compared with a situation in which this relief is available. Table 5 shows that although this difference is small in absolute values (about $€ 1.5$ per months), it is large in a relative sense. In particular, the WTP is approximately $70 \%$ larger in the case where the government does not provide damage relief. A Mann-Whitney- $U$ test indicates that the WTP for flood insurance in the Netherlands is significantly higher ( $p$ value $<0.01$ ), if the government provides no relief after floods and damage can only be compensated through private insurance.

Different results are obtained about the influence of government relief on insurance demand in Germany and the Netherlands. Whereas in the Netherlands the existence of a governmental compensation scheme seems to hamper the development of a private flood insurance market, this is not the case in Germany. These results contradict the hypothesis (H4) that the more frequent experience of governmental aid in Germany has a larger effect on the crowding out of insurance demand in comparison to areas with less frequent floods, like the Netherlands. A more important factor may be in how far individuals in both countries rely on the government for obtaining compensation for flood damage. The absence of private insurance in the Netherlands may have created stronger expectations that the government will compensate flood damage than in Germany where private flood insurance is available. Moreover, the Dutch may perceive a flood as a relatively rare event with catastrophic potential, a situation in which a government response to compensate damage may be strongly expected.

\section{Conclusions}

Flood risk is characterised as a low-probability high-impact risk in the Netherlands and as a comparatively mediumprobability medium-impact risk in Germany. These differences in risks have also influenced the different flood loss compensation schemes that are in place. Using a theoretical framework (Fig. 1) this study compared the empirical results of two interview surveys of households and analysed how flood insurance demand in the Netherlands and Germany differs according to a variety of influences on this demand 
which are related to differences in flood risk between these two countries, such as individual flood experiences, individual flood risk perceptions and the charity hazard.

The analyses confirm our hypothesis that WTP for insurance against medium-probability medium-impact flood risk in Germany is higher than WTP for insurance against lowprobability high-impact risk in the Netherlands. Concerning the individual factors, it is shown:

- that intense experiences such as evacuation or damage can partly explain the higher level of WTP for flood insurance in Germany;

- that the demand for flood insurance is strongly positively related to individual risk perceptions and that risk perceptions are higher in Germany than in the Netherlands;

- that the absence of private insurance and catastrophic nature of flood risk in the Netherlands may have created stronger expectations that the government will compensate flood damage than in Germany where private flood insurance is available, which partly explains the lower level of WTP in the Netherlands.

The comparison of flood insurance demand in Germany and the Netherlands provides relevant information for policy makers who are involved in the design of flood insurance schemes and insurers. Although in the Netherlands flood risks are not generally covered in property insurance policies, results of the survey show that many Dutch homeowners have a positive WTP for flood insurance which indicates that opportunities may exist for introducing flood insurance coverage. However, experience with flood insurance in Germany suggests that despite a sufficiently high demand for flood insurance among a certain part of the population, the market penetration of voluntary insurance will be far from full coverage, which would create pressure on the government to compensate damage of uninsured households after a flood event. An implication of our results of the influence of the charity hazard on flood insurance demand in the Netherlands is that the existence of possible government compensation for flood damage crowds out demand for private flood insurance. A possible solution for this may be to make insurance compulsory as discussed in Germany. Our findings that individual flood risk perceptions are positively related to flood insurance demand in both countries suggest that another way to increase uptake of insurance could be to undertake information campaigns aiming at increasing awareness of flood risks. Such an information campaign could be especially relevant for the Netherlands where actual experiences with flooding are rare, which can result in insufficient preparedness for flooding according to our results; such a campaign could also have merit for Germany. Future research could examine why flood experiences have different impacts on flood insurance demand in different regions.
Acknowledgements. The German research was funded by the German Ministry of Education and Research (BMBF) within the framework of the project MEDIS - Methods for the Evaluation of Direct and Indirect Flood Losses (No. 0330688). Provision of data by GFZ German Research Centre for Geosciences and the Deutsche Rückversicherung $\mathrm{GmbH}$ is gratefully acknowledged. The Dutch research was carried out as part of the Dutch National Research Programme "Climate Changes Spatial Planning" (www.klimaatvoorruimte.nl), and has been partly funded by the Netherlands Organisation for Scientific Research (NWO).

Edited by: B. D. Malamud

Reviewed by: two anonymous referees

\section{References}

Aerts, J. C. J. H., Sprong, T. A., and Bannink, B. (Eds): Aandacht voor Veiligheid, Rapport BSIK programma Klimaat voor Ruimte no. 009/2008, ISBN 978-90-8815-004-3, VU University Press, Amsterdam, 2008.

Berz, G., Kron, W., Loster, T., Rauch, E., Schimetschek, J., Schmieder, J., Siebert, A., Smolka, A., and Wirtz, A.: World map of natural hazards: A global view of the distribution and intensity of significant exposures, Nat. Hazards, 23, 443-465, 2001.

Besley, T. and Burgess, R.: The political of government responsiveness: Theory and evidence from India, Quarterly J. Econom., 117, 1415-1451, 2002.

Bogenrieder, O.: Vortrag auf dem Dresdner Forum zur Versicherungsmathematik 2004, available at: http://www.math. tu-dresden.de/sto/schmidt/verein/2004_Dresdner_Forum/ bogenrieder.pdf (last access: 8 August 2010), 2004 (in German).

Botzen, W. J. W. and van den Bergh, J. C. J. M.: Insurance against climate change and flooding in the Netherlands: Present, future, and comparison with other countries, Risk Anal., 28, 413-426, 2008.

Botzen, W. J. W. and van den Bergh, J. C. J. M.: Bounded rationality, climate risks and insurance: Is there a market for natural disasters?, Land Econom., 85, 266-279, 2009.

Botzen, W. J. W., van den Bergh, J. C. J. M., and Aerts, J. C. J. H.: Report on a Survey about Perceptions of Flood Risk, Willingness to pay for Flood Insurance, and Willingness to Undertake Mitigation Measures: Explanation of the Survey Instrument, Report, September, 2008, VU University, Amsterdam, available at: http://ivm45.ivm.vu.nl/adaptation/project/\%20risk.pdf, last access: 20 January 2013, 2008.

Botzen, W. J. W., Aerts, J. C. J. H., and van den Bergh, J. C. J. M.: Willingness of homeowners to mitigate climate risk through insurance, Ecol. Econom., 68, 2265-2277, 2009a.

Botzen, W. J. W., Aerts, J. C. J. H., and van den Bergh, J. C. J. M.: Individual flood risk perceptions and their relations with socio-economic and objective risk factors, Water Resour. Res., 45, W10440, doi:10.1029/2009WR007743, 2009b.

Botzen, W. J. W., van den Bergh, J. C. J. M., and Bouwer, L. M.: Climate change and increased risk for the insurance sector: A global perspective and an assessment for the Netherlands, Nat. Hazards, 52, 577-598, 2010.

Botzen, W. J. W. and van den Bergh, J. C. J. M.: Risk attitudes to low-probability, high- impact climate change risk: WTP for flood insurance, J. Econ. Behavior Organ., 82, 151-166, 2012a. 
Botzen, W. J. W. and van den Bergh, J. C. J. M.: Monetary valuation of insurance against flood risk under climate change, Int. Econom. Rev., 53, 1005-1025, 2012 b.

Bouwer, L. M., Huitema, D., and Aerts, J. C. J. H.: Adaptive flood management: The role of insurance and compensation in Europe, Report of the NeWater project, Institute for Environmental Studies, VU University Amsterdam, 2007.

Browne, M. J. and Hoyt, R. E.: The demand for flood insurance: Empirical evidence, J. Risk Uncertain., 20, 291-306, 2000.

Burn, D. H.: Perceptions of flood risk: A case study of the Red River flood of 1997, Water Resour. Res., 35, 3451-3458, 1999.

CEA: Reducing the social and economic impact of climate change and natural catastrophes insurance solutions and public-private partnerships. CEA Insurers of Europe, Brussels, available at: http://www.cea.eu/uploads/DocumentsLibrary/ documents/Climate\%20Change\%20report\%20final.pdf (last access: 8 October 2010), 2005.

de Moel, H., van Alphen, J., and Aerts, J. C. J. H.: Flood maps in Europe - methods, availability and use, Nat. Hazards Earth Syst. Sci., 9, 289-301, doi:10.5194/nhess-9-289-2009, 2009.

Dixon, L., Clancy, N., Seabury, S. A., and Overton, A.: The National Flood Insurance Program's Market Penetration Rate: Estimates and Policy Implications, American Institutes for Research, Washington DC, 2006.

DKKV: Hochwasservorsorge in Deutschland-Lernen aus der Katastrophe 2002 im Elbegebiet, Schriftenreihe des DKKV 29, Lessons Learned, Deutsches Komitee für KatastrophenvorsorgeGerman Committee for Disaster Reduction (DKKV), Bonn, 2003 (in German).

EC: Directive 2007/60/EC of the European parliament and of the council of 23 October 2007 on the assessment and management of flood risks, L 288/27, 2007.

Faure, M. G.: Financial compensation for victims of catastrophes: A law and economics perspective, Law Policy, 29, 339-367, 2006.

Flynn, J., Slovic, P., Mertz, C. K., and Carlisle, C.: Public support for earthquake risk mitigation in Portland, Oregon, Risk Anal., 19), 205-216, 1999.

Garrett, T. A. and Sobel, R. S.: The political economy of FEMA disaster payments, Econom. Inq., 41, 496-509, 2003.

GDV: 2003 Yearbook - The German Insurance Industry, Verlag Versicherungswirtschaft, Karlsruhe, German Insurance Association (GDV), available at: https://secure.gdv.de/ gdv-veroeffentlichungen/upload_img/67_dwl.pdf (last access: 8 October 2010), 2003.

GDV: Geo-Informationssystem ZÜRS Geo: Zonierungssystem für Überschwemmungsrisiko und Einschätzung von Umweltrisiken, German Insurance Association (GDV), available at: http://www.gdv.de/Themen/Schadensverhuetung/ NaturgewaltenElementarschaeden/inhaltsseite22828.html (last access: 8 October 2010), 2008 (in German).

Graff, A.: Elmentarrisiken privater Haushalte: die Handhabung finanzieller Schäden in Deutschland - derzeitige Situation und Verbesserungsvorschläge, Regensburger Beiträge zur betriebswirtschaftlichen Forschung, Verlag Peter Lang, Frankfurt, Phdthesis, University Regensburg, 2000 (in German).

Grossi, P. and Kunreuther, H.: Catastrophe Modelling: A New Approach of Managing Risk, Springer, New York, 2005.

Hall, J. W., Evans, E. P., Penning-Rowsell, E. C., Sayers, P. B., Thorne, C. R., and Saul, A. J.: Quantified scenarios analysis of drivers and impacts of changing flood risk in England and Wales: 2030-2100, Environ. Hazards, 5, 51-65, 2003.

ICPR: Atlas on the Risk of Flooding and Potential Damage due to Extreme Floods of the Rhine, The International Commission for Protection of the Rhine, Koblenz, 2001.

IKSE (Internationale Kommission zum Schutz der Elbe): Bestandsaufnahme des vorhandenen Hochwasserschutzniveaus im Einzugsgebiet der Elbe, IKSE, Magdeburg, available at: http: //www.ikse-mkol.org/index.php?id=477\&L=0, last access: June 2013, 2001.

IKSE (Internationale Kommission zum Schutz der Elbe): Aktionsplan Hochwasserschutz Elbe, IKSE, Magdeburg, available at: http://www.ikse-mkol.org/index.php?id=82, last access: June 2013, 2003.

Jongejan, R. and Barrieu, P.: Insuring large-scale floods in the Netherlands, Geneva Papers on Risk and Insurance - Issues and Practice, 33, 250-268, 2008.

Jonkman, S. N.: Global perspectives on loss of human life caused by floods, Nat. Hazards, 34, 151-175, 2005.

Kahneman, D., Slovic, P., and Tversky, A.: Judgment under Uncertainty: Heuristics and Biases, Cambridge University Press, New York, 1982.

Kleist, L., Thieken, A. H., Köhler, P., Müller, M., Seifert, I., Borst, D., and Werner, U.: Estimation of the regional stock of residential buildings as a basis for a comparative risk assessment in Germany, Nat. Hazards Earth Syst. Sci., 6, 541-552, doi:10.5194/nhess-6-541-2006, 2006.

König, R.: Die Elementarschadenversicherung in der Bundesrepublik Deutschland als Element der finanziellen Risikovorsorge gegen Naturereignisse, Band 4 von Schriften zur Politischen Ökonomik, No. 4, Evolutorische und ökologische Aspekte, Peter Lang, Europäischer Verlag der Wissenschaften, Frankfurt, Phdthesis, University Hannover, 2006 (in German).

Krantz, D. H. and Kunreuther, H. C.: Goals and plans in decision making, Judgment Decision Making, 2, 137-168, 2007.

Kriesel, W. and Landry, C.: Participation in the National Flood Insurance Program: An empirical analysis for coastal properties, J. Risk Insurance, 71, 405-420, 2004.

Kreibich, H. and Thieken, A. H.: Coping with floods in the city of Dresden, Germany, Nat. Hazards, 51, 423-436, 2009.

Kreibich, H., Thieken, A. H., Petrow, Th., Müller, M., and Merz, B.: Flood loss reduction of private households due to building precautionary measures - lessons learned from the Elbe flood in August 2002, Nat. Hazards Earth Syst. Sci., 5, 117-126, doi:10.5194/nhess-5-117-2005, 2005.

Kreibich, H., Seifert, I., Thieken, A. H., Lindquist, E., Wagner, K., and Merz, B.: Recent changes in flood preparedness of private households and businesses in Germany, Region. Environ. Change, 11, 59-71, 2011.

Kron, W.: Flood risk = hazard •exposure •vulnerability, International Water Resources Association, Water International, 30, 5868, 2005.

Kron, W.: Flood insurance: from clients to global financial markets, J. Flood Risk Manage., 2, 68-75, 2009.

Kundzewicz, Z. W., Ulbrich, U., Brücher, T., Graczyk, D., Krüger, A., Leckebusch, G. C., Menzel, L., Pinskwar, I., Radziejewski, M., and Szwed, M.: Summer floods in Central Europe: climate change track?, Nat. Hazards, 36, 165-189, 2005. 
Kunreuther, H. C.: Causes of underinsurance against natural disasters, The Geneva Papers on Risk and Insurance, 9, 206-220, 1984.

Kunreuther, H. C.: Mitigating disaster losses through insurance, J. Risk Uncertain., 12, 171-187, 1996.

Kunreuther, H. C.: Rules rather than discretion: Lessons from Hurricane Katrina, J. Risk Uncertain., 33, 101-116, 2006.

Kunreuther, H. C. and Pauly, M.: Neglecting disaster: Why don't people insure against large losses?, J. Risk Uncertain., 28, 5-21, 2004.

Kunreuther, H. C., Michel-Kerjan, E. O., Doherty, N. A., Grace, M. F., Klein, R. W., and Pauly, M. V.: At War with the Weather: Managing Large-Scale Risks in a New Era of Catastrophes, 1st Edn., The MIT Press, Cambridge, MA, 2009.

Kunreuther, H. C., Michel-Kerjan, E. O., Doherty, N. A., Grace, M. F., Klein, R. W., and Pauly, M. V.: At War with the Weather: Managing Large-Scale Risks in a New Era of Catastrophes, Paperback edition, MIT Press, 2011.

Landtag Rheinland-Pfalz: Antwort des Ministeriums der Finanzen auf die Große Anfrage der Fraktion der CDU "Hilfe bei Hochwasser- und Elementarschäden”, Drucksache 14/4195, 2005 (in German).

Laury, S. K., Morgen-McInnes, M., and Swarthout, J. T.: Insurance decisions for low- probability losses, J. Risk Uncertain., 39, 1744, 2009.

Lewis, T. and Nickerson, D.: Self-insurance against natural disasters, J. Environ. Econom. Manage., 16, 209-223, 1989.

McClelland, G. H., Schulze, W. D., and Coursey, D. L.: Insurance for low-probability hazards: A bimodal response to unlikely events, J. Risk Uncertain., 7, 95-116, 1993.

Michel-Kerjan, E. O.: Catastrophe economics: The National Flood Insurance Program, J. Economic Perspectives, 24, 165-168, 2010.

Michel-Kerjan, E. O. and Kousky, C.: Come rain or shine: Evidence on flood insurance purchases in Florida, J. Risk Insurance, 77, 369-397, 2010.

Mitchell, R. C. and Carson, R. T.: Using Surveys to Value Public Goods: The Contingent Valuation Method, Resources for the Future, Washington DC, 1989.

Mustafa, D.: Reinforcing vulnerability? Disaster relief, recovery and response to the 2001 flood in Rawalpindi, Pakistan, Environ. Hazards, 5, 71-82, 2003.

Norušis, M. J.: SPSS 11.0 Guide to Data Analysis, Prentice Hall, Upper Saddle River, USA, 2002.

Policy Research Corporation: The economics of climate change adaptation in EU coastal areas - Country report Germany, available at: http://ec.europa.eu/maritimeaffairs/documentation/ studies/climate_change_en.htm (last access: 25 February 2013), 2009.

Raschky, P. A. and Weck-Hannemann, H.: Charity hazard: A real hazard to natural disaster insurance?, Environ. Hazards, 7, 321$329,2007$.
Riad, J. K., Norris, F. H., and Ruback, R. B.: Predicting evacuation in two major disasters: Risk perception, social influence and access to resources, J. Appl. Social Psychol., 29, 918-934, 1999.

Rowe, R. D., Schulze, W. D., and Breffle, W. S.: A test of payment card biases, J. Environ. Econom. Manage., 31, 178-185, 1996.

Savage, L. J.: The Foundations of Statistics, Wiley, New York, 1954.

Schwarze, R. and Wagner, G. G.: The political economy of natural disaster insurance: Lessons from the failure of a proposed compulsory insurance scheme in Germany, European Environ., 17, 403-415, 2007.

Schwarze, R. and Wagner, G. G.: Natural Hazards Insurance in Europe: Tailored Responses to Climate Change Needed, Working Papers in Economics and Statistics 2009-06, University of Innsbruck, available at: http://www.uibk.ac.at/fakultaeten/volkswirtschaftund_statistik/ forschung/wopec/repec/inn/wpaper/2009-06.pdf (last access: 8 October 2010), 2009.

Slovic, P.: Perception of risk, Science, 236, 280-285, 1987.

Slovic, P.: Perceptions of Risk, Earthscan, London, 2000.

TAW: From Probability of Exceedance to Probability of Flooding: Towards a New Safety Approach, Technische Adviescommissie voor de Waterkeringen (TAW), Dienst Weg- en Waterbouwkunde, Rijkswaterstaat, Delft, 2000.

te Linde, A. H., Bubeck, P., Dekkers, J. E. C., de Moel, H., and Aerts, J. C. J. H.: Future flood risk estimates along the river Rhine, Nat. Hazards Earth Syst. Sci., 11, 459-473, doi:10.5194/nhess-11-459-2011, 2011.

Thieken, A. H., Seifert, I., and Merz, B. (Eds.): Hochwasserschäden: Erfassung, Abschätzung und Vermeidung, Oekom, 2010 (in German).

Thieken, A. H., Müller, M., Kreibich, H., and Merz, B.: Flood damage and influencing factors: New insights from the August 2002 flood in Germany, Water Resour. Res., 41, W12430, doi:10.1029/2005WR004177, 2005.

Thieken, A. H., Petrow, T., Kreibich, H., and Merz, B.: Insurability and mitigation of flood losses in private households in Germany, Risk Anal., 26, 383-395, 2006.

Thieken, A. H., Kreibich, H., Müller, M., and Merz, B.: Coping with floods: Preparedness, response and recovery of flood-affected residents in Germany in 2002, Hydrol. Sci. J., 52, 1016-1037, 2007.

van Dantzig, D.: Economic decision problems for flood prevention, Econometrica, 24, 276-287, 1956.

Vogt, J. P., Soille, A., de Jager, E., Rimaviciute, W., Mehl, S., Foisneau, K., and Bodis, U. A.: A pan-European river and catchment database, European Commission, 2007.

Zahrahn, S., Weiler, S., Brody, S. D., Lindell, M. K., and Highfield, W. E.: Modeling national flood insurance policy holding at the county scale in Florida, 1999-2005, Ecol. Econom., 68, 26272636, 2009. 